\title{
On the Differences in the Intraseasonal Rainfall Variability between Western and Eastern Central Africa: Case of 25 - 70-Day Oscillations
}

\author{
Alain Tchakoutio ${ }^{1,2,3 *}$, Armand Nzeukou ${ }^{2}$ \\ ${ }^{1}$ Department of Computer Science, Higher Technical Teachers Training College (HTTTC), University of Buea, \\ Kumba, Cameroon \\ ${ }^{2}$ Laboratory for Environmental Modeling and Atmospheric Physics, Department of Physics, Faculty of Science, \\ University of Yaoundé 1, Yaoundé, Cameroon \\ ${ }^{3}$ Laboratory of Industrial Systems and Environmental Engineering, Fotso Victor Technology Institute, University \\ of Dschang, Dschang, Cameroon \\ Email: "stchakoutio@yahoo.com
}

Received 5 June 2016; accepted 25 July 2016; published 28 July 2016

Copyright (C) 2016 by authors and Scientific Research Publishing Inc.

This work is licensed under the Creative Commons Attribution International License (CC BY). http://creativecommons.org/licenses/by/4.0/

(c) (i) Open Access

\section{Abstract}

The intraseasonal timescale is critical in Central Africa, because the resources of the region are highly rainfall dependent. In this paper, we use 1DD GPCP rainfall product to investigate the differences in the space-time structures of the 25 - 70-day intraseasonal variability of rainfall, over the Western Central Africa (WCA) and the Eastern Central Africa (ECA), with different climate features. The results of Empirical Orthogonal Functions (EOFs) analysis have shown that the amount of variance explained by the leading EOFs is greater in ECA (58.4\%) than in WCA (49.8\%). For both WCA and ECA, the power spectra of the Principal Components (PCs) peaked around 40 days, indicating a MJO signal. The seasonality of ISO is evident, but this seasonality is much noticeable in ECA where almost $80 \%$ of the total yearly ISO power occurs during November-April season, against only around $60 \%$ for WCA. Moreover, the lagged cross correlations computed between WCA and ECA PCs time series showed that most of the WCA PCs led ECA PCs time series with a timescale of 8 - 12 days, revealing that the eastward propagation could potentially be the relationship between WCA and ECA modes. The interannual variations in the ISO activity are weak in WCA, when compared with ECA where the signal exhibits larger interannual variations, quite linked with ENSO.

\footnotetext{
${ }^{*}$ Corresponding author.
}

How to cite this paper: Tchakoutio, A. and Nzeukou, A. (2016) On the Differences in the Intraseasonal Rainfall Variability between Western and Eastern Central Africa: Case of 25 - 70-Day Oscillations. Journal of Geoscience and Environment Protection, 4, 141-158. http://dx.doi.org/10.4236/gep.2016.47015 


\section{Keywords}

\section{Rainfall, Intraseasonal Variability, Central Africa, EOF Analysis}

\section{Introduction}

It is well-known that climate variability and change are a crucial problem in many tropical regions. Amongst these regions, the Central Africa (CA) is particularly attractive because of the variety of its topography and surface conditions (Table 1). Furthermore CA is particularly vulnerable to climate change, because the economy of many countries is based on agriculture and livestock activities.

The CA extends from $15^{\circ} \mathrm{S}$ to $15^{\circ} \mathrm{N}$ and $5^{\circ} \mathrm{E}-45^{\circ} \mathrm{E}$ mainly over the land and part of Atlantic and Indian oceans on its edges (Figure 1). The topography of the region is much varied, including highlands, mountains, and plateaus (Figure 1(a)). Then higher frequencies climate variability, from daily to intraseasonal timescales is a significant source of vulnerability in the region. The western part of the region $\left(15^{\circ} \mathrm{S}-15^{\circ} \mathrm{N} ; 5^{\circ} \mathrm{E}-30^{\circ} \mathrm{E}\right)$ receives intense precipitation throughout the year, especially over the Congo Basin (Figure 1(b)). This subregion is almost covered by the Congo forest (Figure 1(c)), which keeps it quite relatively wet throughout the year. The eastern part $\left(15^{\circ} \mathrm{S}-15^{\circ} \mathrm{N} ; 30^{\circ} \mathrm{E}-50^{\circ} \mathrm{E}\right)$ is characterized by widely diverse vegetations ranging from desert to forest over relatively small areas. The topography of the region is complex and then influencing climate, because it leads to the orographically induced rainfall and affect local climates [1] [2]. This region has suffered from both excessive and deficient rainfall in recent years [3] [4]. The difference between the East and West boundaries of CA is approximately $3000 \mathrm{~m}$ in surface elevation, and $3000 \mathrm{~mm}$ in annual mean rainfall. Then the two subregions (ECA and WCA), separated from each other by the Rift Valley, are very different in terms of topography, surface conditions and precipitation (Table 1).

The ITCZ (Inter-Tropical Convergence Zone) is a classical and dominant feature of atmospheric dynamics over the region [5] [6]. Then the rainfall over CA is highly seasonal. The peak of ITCZ precipitation belt shifts from north to south of the equator during November-December and returns to north during March-April. The ITCZ precipitation maximizes near $10^{\circ} \mathrm{N}$ during summer, while it peaks near $10^{\circ} \mathrm{S}$ during winter. Around the equator $\left(6^{\circ} \mathrm{S}-6^{\circ} \mathrm{N}\right)$, the mean annual rainfall is divided into four periods or seasons: December-February (DJF), March-May (MAM), June-August (JJA), and September-November (SON).

As stated earlier, the intraseasonal timescale is crucial in CA, because the resources of the region are highly rainfall dependent. Intraseasonal Oscillations (ISO) refer to cycles operating at timescales shorter than a seasonal cycle. In the past three decades, the lack of infrastructure to measure rainfall led many authors to the use of satellite data, such as Outgoing Longwave Radiation (OLR) to study the intraseasonal variability in some tropical regions [7]-[13]. Furthermore it was found in many studies that in Africa rainfall variability, there exists two dominant frequency bands at intraseasonal timescales. For example, analysis was made for Africa and signals over 10 - 25-day and 25 - 60-day periods were found in convection and precipitation in the western region [13].

An important characteristic of the MJO (ISO) is its irregularity within the year, and from year to year, as well as the spatial variations in its intensity and speed. In fact the modulation of the level of MJO activity and its possible predictability is one of the greatest challenges and it has been the key subject of many researches (e.g. [14]-[20]). Moreover in the regions as CA where climate varies over few kilometers, it is interesting to extract many ISO indices, depending on the climate zone. Indeed the CA region represents a notable gap in the study of the tropical climate system. Significantly, the structures of the Intraseasonal Oscillations (ISO) in Central Africa

Table 1. Comparison of some geographical features between eastern and western central Africa.

\begin{tabular}{ccc}
\hline & Western Central Africa (WCA) & Eastern Central Africa (ECA) \\
\hline $\begin{array}{c}\text { Average topography } \\
\text { Vegetation }\end{array}$ & Lower than $700 \mathrm{~m}$ & Greater than $1500 \mathrm{~m}$ \\
Mean annual rainfall & Almost covered by the Congo forest & From desert to minor forests over relatively small areas \\
Borders & Greater than $1600 \mathrm{~mm}$ & Lower than $700 \mathrm{~mm}$ \\
& Rift Valley-Atlantic ocean & Rift Valley-Indian ocean \\
\hline
\end{tabular}


Surface elevation (source:GTOPO30)

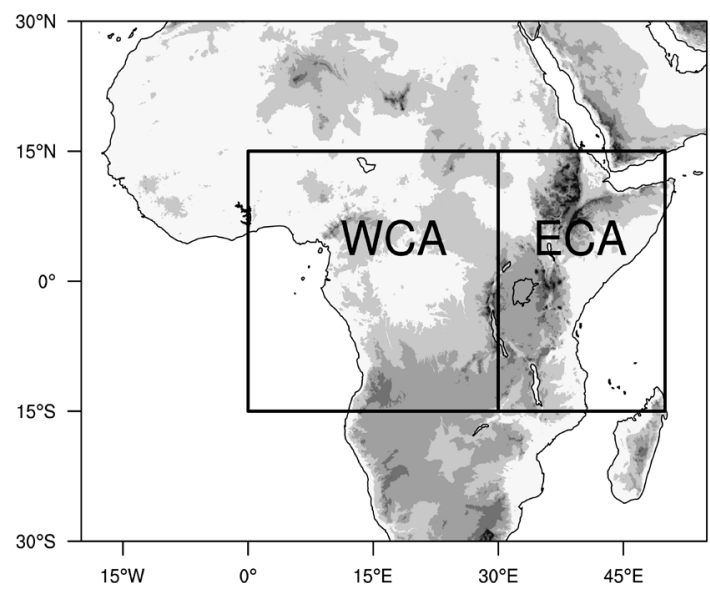

(a)

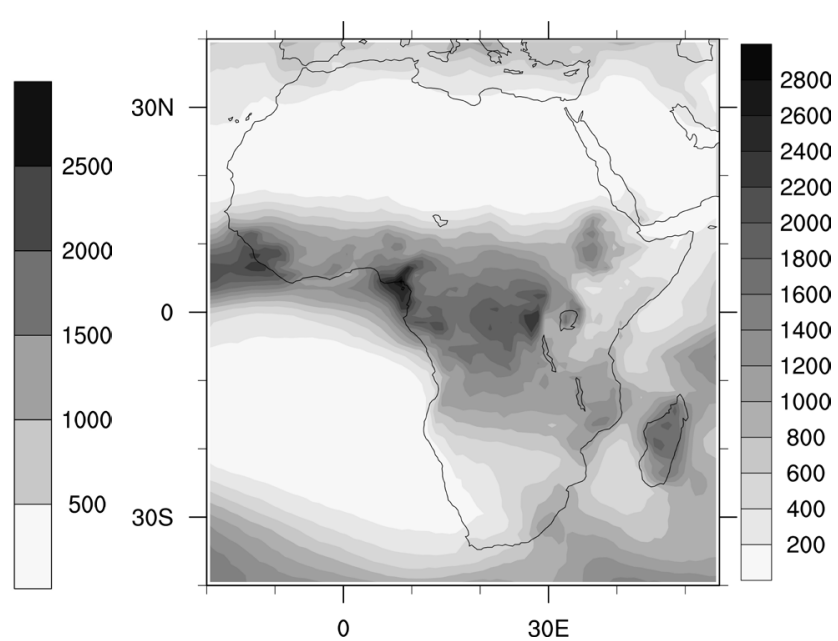

(b)

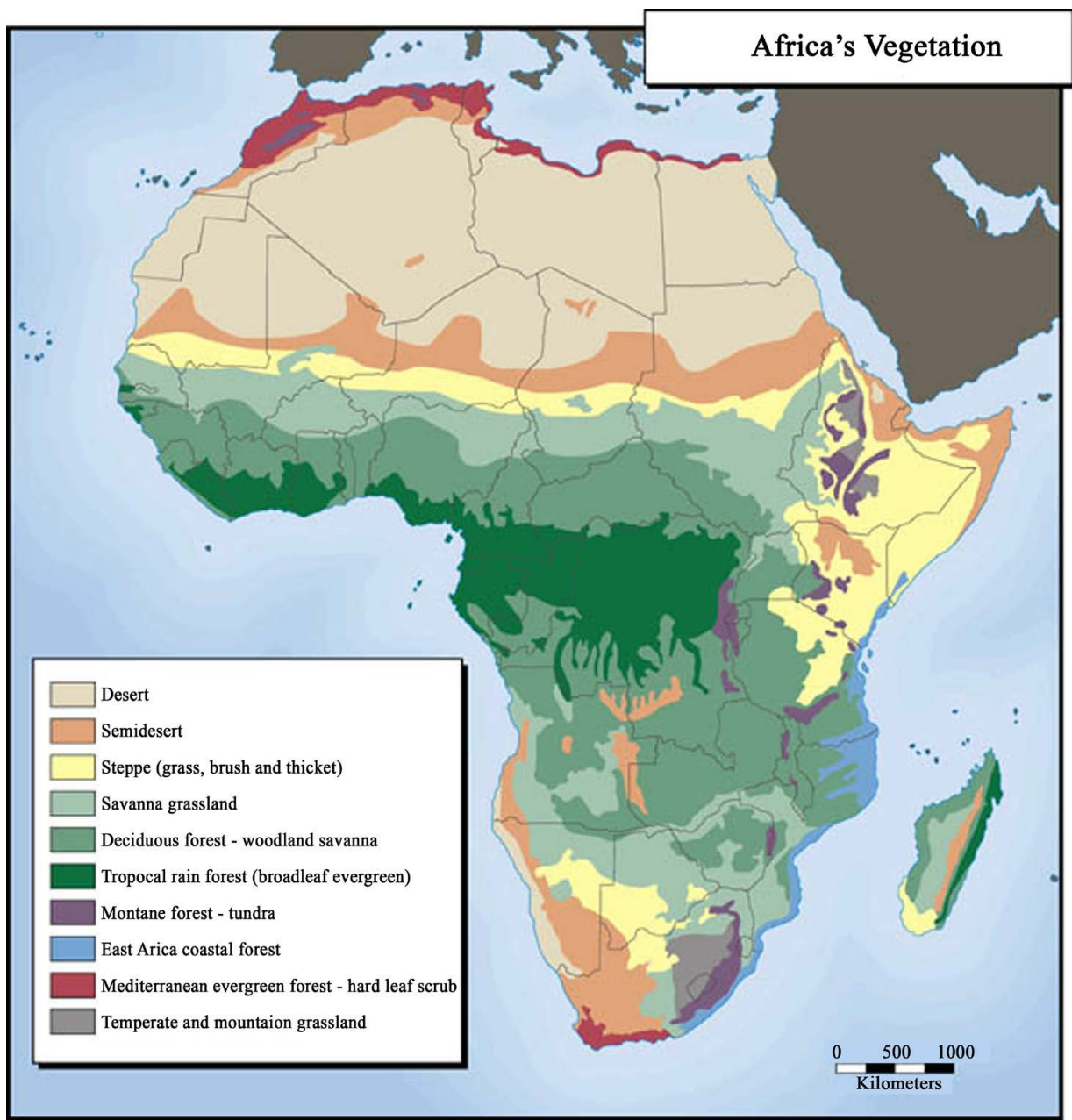

(c)

Figure 1. (a) Surface elevation over the study area based on 30-min topographic data (m) from Digital Elevation Model (DEM) of the US Geological Survey. The study domain $\left(15^{\circ} \mathrm{S}-15^{\circ} \mathrm{N}, 5^{\circ} \mathrm{E}-45^{\circ} \mathrm{E}\right)$ and the division line between WCA and ECA are shown on the plot. (b) Annual mean rainfall, the plot is based on 1DD GPCP precipitation for the period 1996-2009 and the unit of precipitation is mm. (c) Mean vegetation cover, the vegetation density is interpreted as the green level of the surface (source people.virginia.edu). 
are only discussed by few authors. More recently, [19] used one-Degree Daily Global Precipitation Climatology Project (1DD GPCP) higher resolution rainfall product to study the ISO patterns in CA, but they considered the whole area $\left(15^{\circ} \mathrm{S}-15^{\circ} \mathrm{N}, 0^{\circ} \mathrm{N}-50^{\circ} \mathrm{N}\right)$ and did not take into account the contrast patterns between western and eastern parts of the region with different climate features. Fortunately, only [19] addressed this issue. It was proved that there are two dominant frequency bands in the intraseasonal rainfall variability, 10 - 25-day and 25 70-day respectively, but they studied this difference in the intraseasonal oscillations only for 10 - 25-day frequency band. So the present study is a continuity of the work done by [19], for the 25 - 70-day frequency band.

We use the same methods as [19] to assess the detailed spatial and temporal patterns of the leading modes of ISV of rainfall over the region, both throughout the year and from year to another.

The paper is organized as follows: In the next section, the data and methods used will be described. Section 3 will present the main results obtained and the analyses. Finally, Section 4 is devoted to a few discussions and conclusions.

\section{Data and Methods}

\subsection{Data}

For this study, we used the 1DDGPCP rainfall data. The GPCP algorithm combines precipitation estimates from several sources, including infrared (IR) and passive microwave (PM) rain estimates and rain gauge observations [20]-[22]. The IR data came mainly from the different Geostationary Meteorological Satellites but data from polar-orbiting satellites were also used to fill in the gaps at higher latitudes. The IR based estimates used the Geostationary Operational Environmental Satellite (GOES) precipitation index (GPI) described by [23]. The microwave data come mainly from the Special Sensor Microwave Imager (SSM/I) on board the Defense Meteorological Satellite Program. The PM estimates were used to adjust the GPI estimate. Then, the multi-satellite estimate was adjusted towards the large-scale gauge average for each gridbox. The gauge-adjusted multi-satellite estimates were then combined with gauge analysis using a weighted average, where the weights are the inverse error variances of the respective estimates. The current products include a monthly analysis at $2.5^{\circ} \times 2.5^{\circ}$ longitude-latitude grids, a 5-day (pentad) analysis at the same spatial resolution, and a daily product at a special resolution of one degree. The one-degree daily (1DD) product does not use PM rain estimates and gauge measurements directly [21]. SSM/I data were used within the frame work of the threshold-matched precipitation index (TMPI) to delineate rain are as in the IR data. Gauge data were involved indirectly when the 1DD product was scaled so that monthly accumulations of 1DD matched the monthly GPCP product. The monthly and pentad analyses extend from 1979 to current, while the daily product is available starting from October 1996. The daily products are made available 2 to 3 months after the end of each month. The product used in this paper is the one-degree daily precipitation data available on the NOAA website

http://www.esrl.noaa.gov/psd/data/gridded/data.gpcp.html. After some global and regional validations [24]-[26], the GPCP rainfall estimates are actually being used widely in place of gauge observations or to supplement gauge observations in the climate variability studies.

The Niño-3.4 region $\left(5^{\circ} \mathrm{S}-5^{\circ} \mathrm{N}, 160^{\circ} \mathrm{E}-150^{\circ} \mathrm{W}\right)$ sea surface temperature anomaly (SSTA) index was also used, to define the strength of ENSO and identify individual El Niño and La Niña events [27]. These Monthly observed SSTA are adapted from the National Oceanic and Atmospheric Administration (NOAA Climate Diagnostics Center).

\subsection{Methods}

Depending on the purpose of analysis, some frequencies may be of greater interest than others, and it may be helpful to reduce the amplitude of variations at other frequencies by statistically filtering them out before viewing and analyzing the series. The Lanczos filtering [28] used in this study is one of the Fourier methods of filtering digital data. Its principal feature is the reduction of the amplitudes of Gibbs oscillation. The Fourier coefficients for the smoothed response function are determined by multiplying the original weight function $w_{k}$, by a function that Lanczos called "sigma factors". Then the weight function of relation becomes [29]:

$$
\bar{w}_{k}=\frac{\sin 2 \pi k f_{c}}{\pi k} \cdot \frac{\sin \pi k / n}{\pi k / n}
$$


where $w_{k}=\frac{\sin 2 \pi k f_{c}}{\pi k}$ are the traditional Fourier weights. The Lanczos filter is widely used for filtering climate data time series.

Commonly, some form of time series or spectral analysis is used for extracting periodic signatures from a set of data pertaining to climate variations. Fourier series provides an alternate way of representing data: instead of representing the signal amplitude as a function of time, we represent the signal by how much information is contained at different frequencies. A Fourier series takes a signal and decomposes it into a sum of sines and cosines of different frequencies.

$$
f(t)=a_{0}+\sum_{n=1}^{+\infty} a_{n} \cos (2 \pi n t)+b_{n} \sin (2 \pi n t)
$$

where $f(t)$ is the signal in the time domain, and $a_{n}$ and $b_{n}$ are unknown coefficients of the series, which can be found by simple integration. In atmospheric sciences, we generally work with discrete data points, not an analytical function that we can analytically integrate. It turns out that taking a Fourier transform of discrete data is done by simply taking a discrete approximation to the integrals. Inversely, the Fourier Transform generates values of amplitudes and phases averaged over the entire time series for each frequency component or harmonic. The amplitude of signal can then be represented as a frequency, and the dominant frequencies are highlighted.

The Wavelet Analysis (WA) is a time series analysis method that has increasingly been applied in geophysics during the last three decades (e.g. [30] [31]). It is becoming a common tool for analyzing temporal variations of power within a time series. The transformation in time series from the time space into the time-frequency space show that, the WA is able to determine both the dominant timescales of variability and how they vary with time. WA has several attractive advantages over the traditional spectral analysis, especially when dealing with time series with time-varying amplitudes. In contrast to the Fourier Transform, that generates values of amplitudes and phases averaged over the entire time series for each frequency component or harmonic, Wavelet Transform provides a localized instantaneous estimate of the amplitude and phase for each spectral component of the series. This gives WA an advantage in the analysis of non-stationary data in which the amplitude and phase of the harmonic components may change rapidly in time or space. While the Fourier Transform of the non-stationary time series would smear out any detailed information on the changing features, the WA keeps track of the evolution of the signal characteristics throughout the time series. Further details on wavelet analysis can be found in [32].

In the last several decades, meteorologists have in fact put major efforts in extracting important patterns from measurements of atmospheric variables. As a result Empirical Orthogonal Functions (EOF) technique has become the most widely used way to do this [33]-[35]. The original purpose of EOFs was to reduce the large number of variables of the original data to a few variables, but without compromising much of the explained variance. Lately, however, EOF analysis has been used to extract individual modes of variability (e.g. [15] [17] [28]-[30] in a data time series. In the EOF analysis, the time-dependent deviations from the long-term mean are decomposed into a sum of products of fixed spatial patterns $p_{k}$ and time-dependent amplitudes $\alpha_{k}$ (the principal components) as follows:

$$
f\left(x_{i}, t\right)=\sum p_{k}\left(x_{i}\right) \alpha_{k}(t)
$$

where the principal components $\alpha_{k}$ are uncorrelated to one another and described subsequently a maximum of variance in the original anomalies field $f$. Under these conditions the EOFs $p_{k}$ are eigenvectors of the covariance matrix of $f$.

The eigen value $\lambda_{k}$ corresponding to the $k^{\text {th }}$ EOF gives a measure of the explained variance by $\alpha_{k}$. It is usual to write the explained variance in percentage as:

$$
100 \cdot \frac{\lambda_{k}}{\sum_{i=1}^{p} \lambda_{i}} \%
$$

Rotated EOF (REOF) is a technique simply based on rotating EOFs. REOF techniques have been adopted by atmospheric scientists since the mid-eighties as an attempt to overcome some of the previous short comings such as the difficulty of physical interpretability. The technique, however, is much older and goes back to the early fourties. The technique is also known in factor analysis as factor rotation and aims at getting simple structures. In meteorology the objective was to alleviate the strong constraints of EOFs, namely orthogonality/uncorrelation 
of EOFs/PCs, domain dependence of EOF patterns, obtain simple structures, and be able to physically interpret the patterns. Initially, a standard EOF analysis is performed and an EOF subset is retained; and subjected to varimax rotation. Some think that the resulting patterns are more physically interpretable. The patterns may still be domain dependent.

The above described mathematical tools (Lanczos filtering, Fourier analysis, wavelet analysis and EOFs analysis) are simultaneously used in this paper. Briefly the long-term OLR anomalies are firstly passed through the high-pass Lanczos filter with 120 days cut off in order to remove low frequencies modes such as interseasonal and interannual variability. Morlet wavelet is applied to the output time series to extract the relevant information. After the wavelet analysis, the timescales where the intraseasonal signal power is relatively high are detected. The original time series are now passed through a band-pass Lanczos filter to retain only the cycles with periods within the relevant timescales. The filtered data-sets have then been subjected to EOF analysis with varimax rotation and the leadings PCs are retained according to the Scree test [33] and the North criteria [34]. After the PCs time series have been extracted, we studied the variations in the ISO magnitude and frequency used statistical methods.

\section{Results and Discussions}

\subsection{Spectral Analysis}

In [35], they firstly carried out the spectral analysis on the daily rainfall time series, to highlight the dominant frequency band. Then for every day, we averaged the data of all grid points in WCA and ECA. The spectral analysis was then performed on the two daily area mean time series obtained. Using classical Fourier analysis, the power spectra in the two sub-regions showed the dominance of the intraseasonal variability in Central African rainfall (Figure 2). At intraseasonal timescales, the highest peaks of rainfall variability are centered near 50 days, and extended over the longer periods (35 - 80 day, corresponding to frequencies $0.0125-0.03$ day $^{-1}$ ). However, this dominance is less pronounced in WCA, because of many relative peaks observed at different frequencies, even in synoptic scale. The fraction of total variance occurring in the 35- to 80-day range is 0.33 for WCA and 0.48 for ECA. On the other hand, Wavelet analysis helped us to have some additional information (Figure 3(a), Figure 3(b)). Figure 3 clearly revealed two dominant bands of higher wavelet powers in the ECA spectrum (10 - 25 days and 25 - 70 days), both in WCA and ECA. But the relative importance of synoptic scale in WCA rainfall do not allows the intraseasonal timescales to be well-highlighted. This confirms that in WCA,

WCA

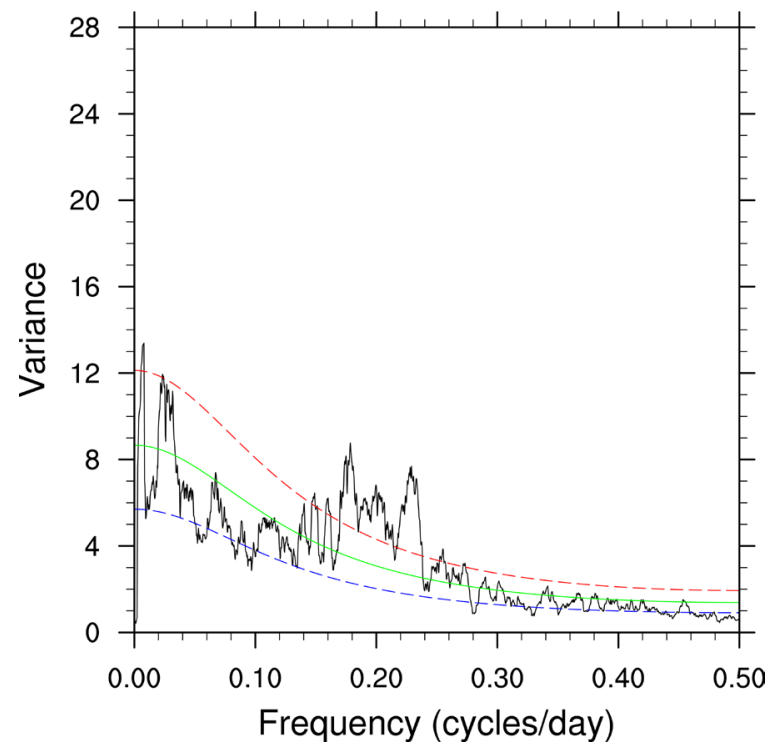

(a)

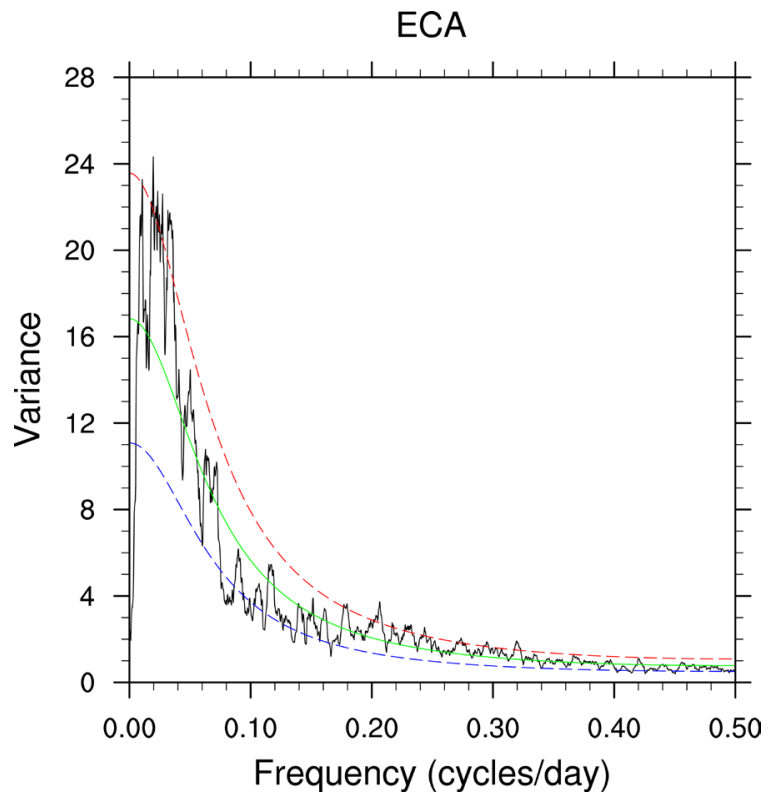

(b)

Figure 2. Calculated spectrum (solid black), red noise curve (green solid) and the curves indicating the upper (red dashed) and lower (blue dashed) confidence bounds, for WCA (left) and ECA (right) sub-regions. 


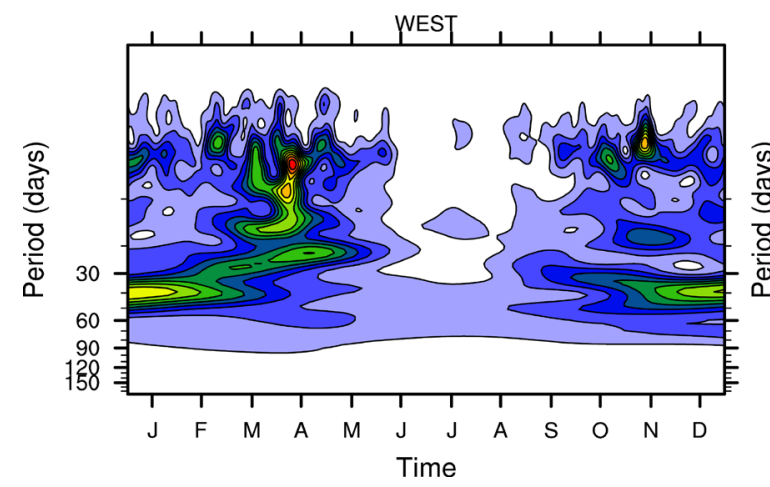

(a)

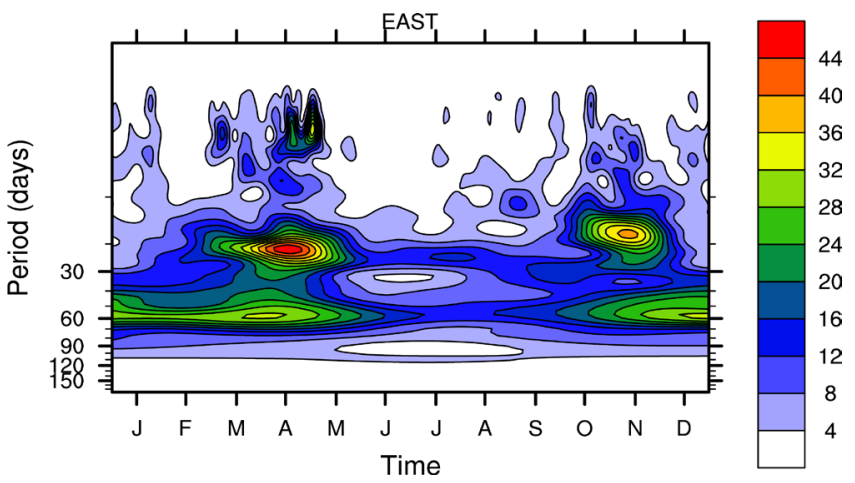

(b)

Figure 3. Annual mean wavelet power of the rainfall anomalies averaged over WCA (a) and ECA (b). A 120 days cut off high pass filter was applied to long term anomalies in order to remove low frequencies variability such as interseasonal and interannual variability.

the mechanisms that induce variability are much varied. At the synoptic scale, the spectral power peaks near 5 days both in the two sub-regions. This result is consistent to that found by some previous authors (e.g. [13] [17] [28] [29] [35] [36]) with daily OLR datasets over West Africa. The seasonality of ISO is clearly revealed, showing the maximum wavelet power during the beginning and end of the year (December-April). This seasonality can be explained by the location of study area along the equator [37].

\subsection{Intraseasonal Oscillations}

From the spectral analysis performed above and following the work of [35], we filtered the rainfall anomalies in this study between 25 - 70 days, to derive the space-time structures of the leading EOFs of intraseasonal variability of rainfall, corresponding to this frequency band. Once more, all these analyses are performed separately in ECA and WCA. The leading modes are retained, and spatial loadings associated with a given mode are obtained by computing the correlation coefficients between the corresponding PC's time series and the filtered data field.

The 25 - 70-day mode is also known as the "African MJO" mode [17], in reference to the Madden-Julian Oscillation detected over the Indian and West Pacific sectors [38]. Over WCA, The first two EOFs exhibit a negative correlation, while the third EOF exhibits a positive correlation with the 25 - 70-day filtered rainfall data (Figure 4). Over ECA, the first and third EOFs exhibit positive correlation with filtered precipitation, while the second shows negative loadings. The power spectra of the three leading EOFs peaks near 45 days both over ECA and WCA (Figure 5), indicating MJO signal. The amount of the total variance explained by the leading EOFs is smaller in WCA (49.8\%) than ECA (58.4\%), suggesting that 25 - 70 days filter rainfall time series in WCA also have more degree of freedom than ECA time series, in consistency with the previous analyses.

As for 10 - 25 days mode [35], the amplitude time series reveals a difference between ECA and WCA rainfall oscillations. WCA experiences oscillation almost throughout the year (Figures 6(a)-(c)), while the ISO are highly seasonal in ECA (Figures 8(d)-(f)) with significant oscillations during October-April.

\subsection{Annual and Interannual Variation in the ISO Activity}

Since it was shown in the previous studies that the ISO undergo harsh variations within the year and from year to another, we address the issue in this study much quantitatively, by plotting the ISO strength in the two subregions (WCA and ECA) during the study period. In fact the ISO are affected by the seasonal cycle through one or more seasonally dependent energy sources [39]. The seasonal forcing governs the amplitude of the intraseasonal oscillations. Equally, the ISO provides feedback - turning the annual cycle "on" and "off". One of the greatest challenges of climate variability studies remains to show accurately how these seasonal variations can affect the local annual cycle of rainfall over a given region. An answer to this question may greatly contribute to improve regional models in the tropics.

In order to study much quantitatively the annual variations of ISO strength, an ISO index was built, by taking the total daily 25 - 70-day wavelet powers, of the leading principal components [28] [29] [35]. The times series 

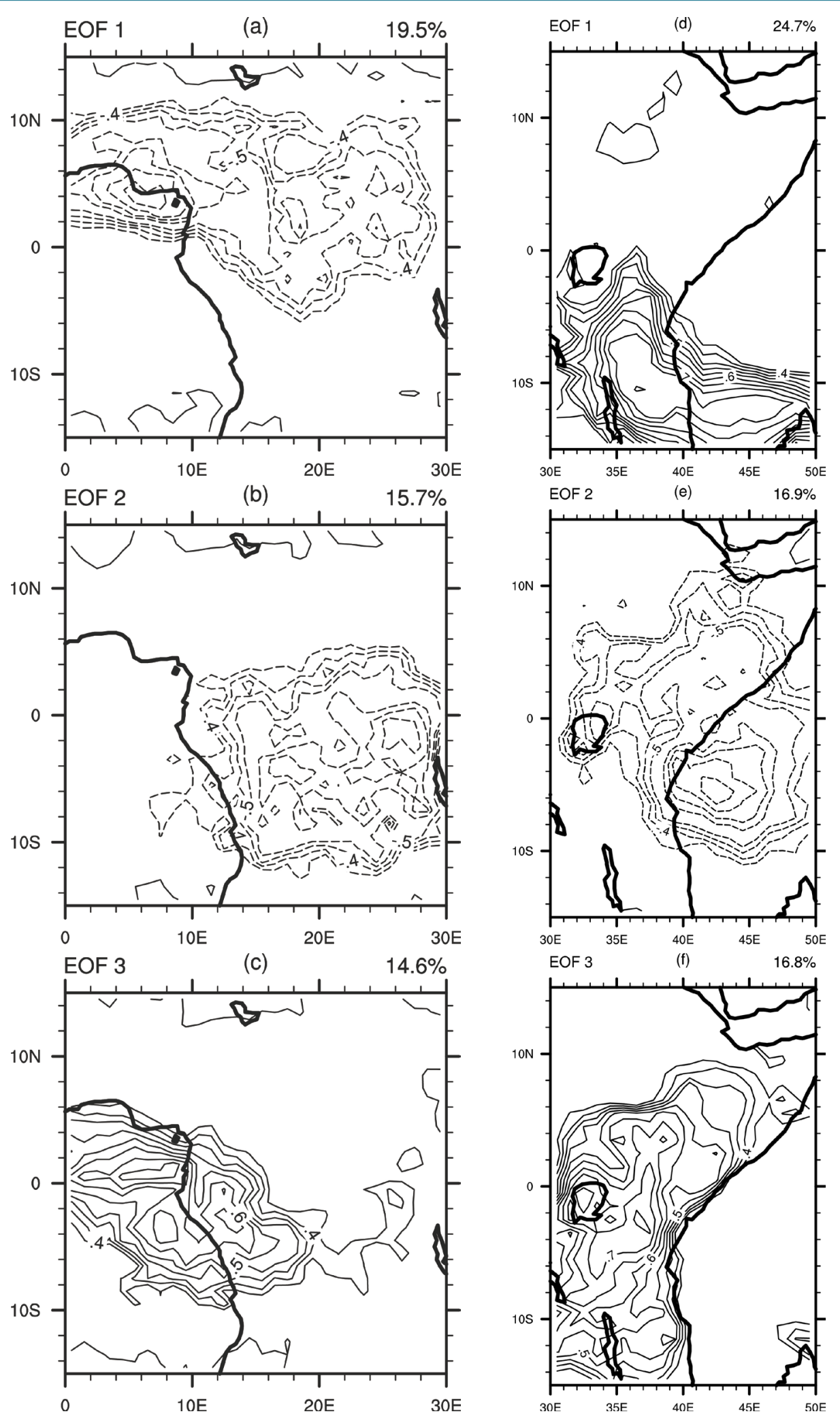

Figure 4. Correlation coefficient map (loadings) between rainfall anomalies field and PCs for WCA ((a)-(c)) and ECA ((d)(f)). PCs were computed using the whole time series of daily rainfall for the period 1996-2009. Contour intervals are plotted every 0.05 and correlations in between -0.2 and 0.2 are omitted. The negative correlations are represented as dashed line and the positive correlation the solid lines. 

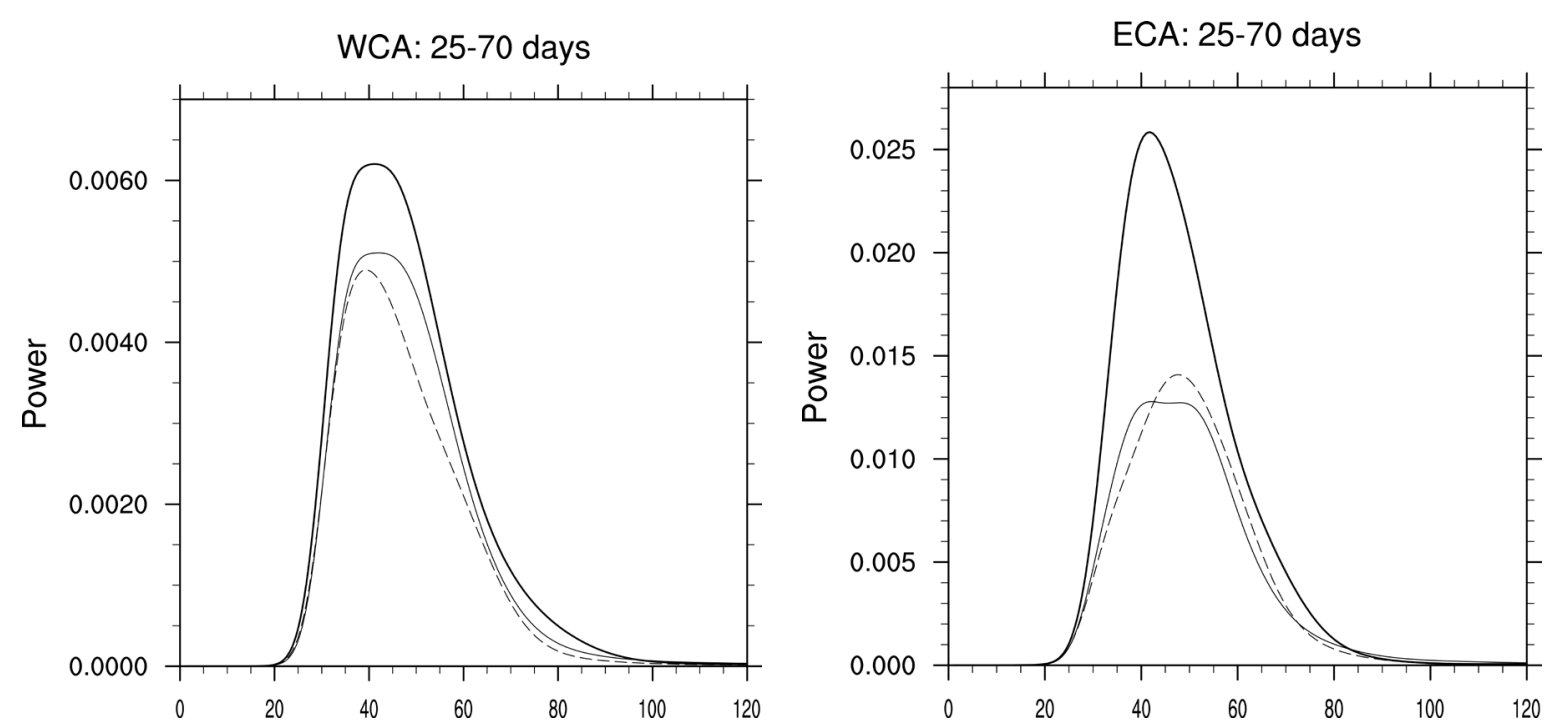

Figure 5. Power spectra of PC1 (bold solid), PC2 (thin solid), and PC3 (thin dashed), respectively over WCA (left top and left bottom) and ECA (right top and right bottom). The scale of the x-axis is in days for all plots and the power dimensionless because the anomalies field is normalized.

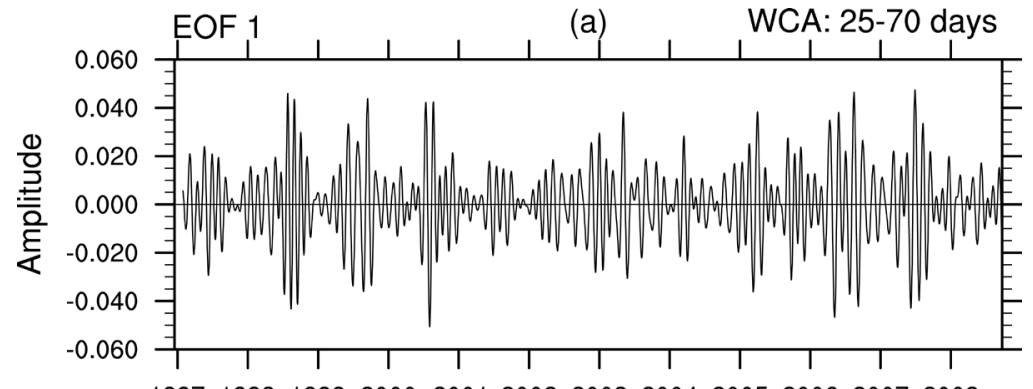

199719981999200020012002200320042005200620072008

Years

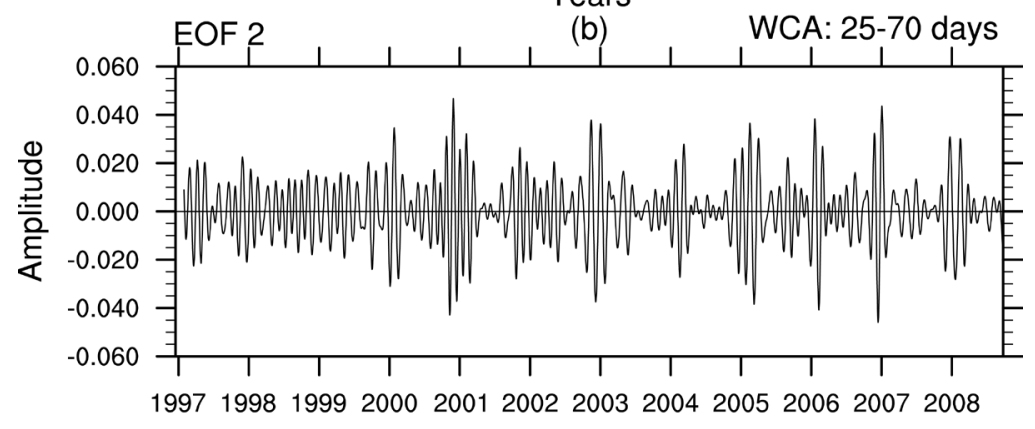

Years

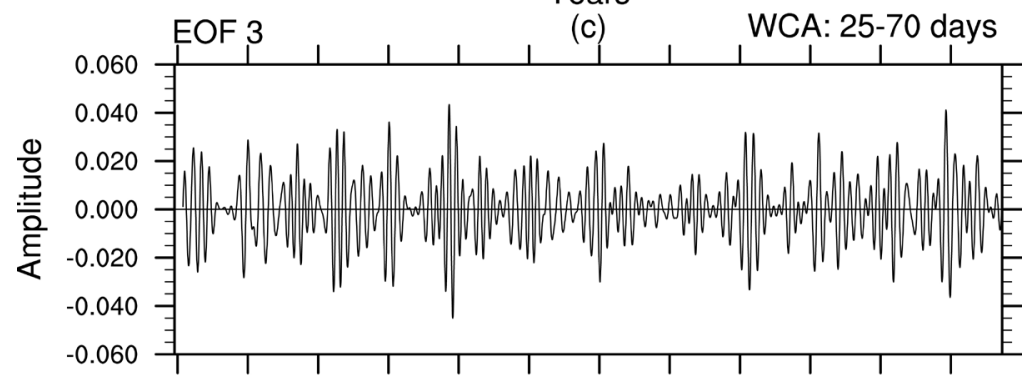

199719981999200020012002200320042005200620072008

Years 

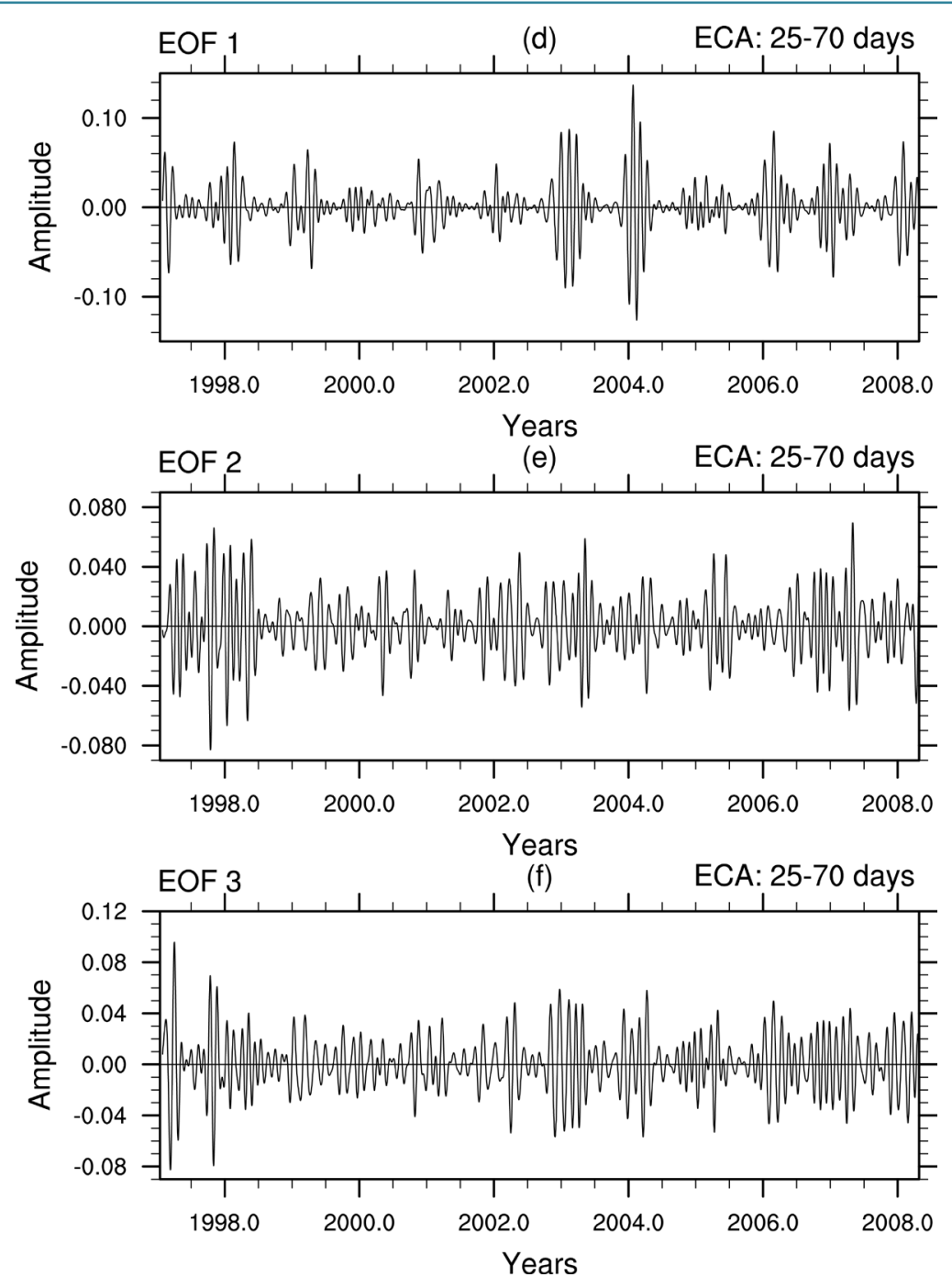

Figure 6. Principal components (scores) time series of the 25 - 70-day filtered rainfall data over WCA (left) and ECA (right).

obtained have then in WCA and ECA been normalized for easy comparison. In Figure 7 is represented the cumulative percentage mean power, as function of the day of the year. Once again, it can be seen that in the eastern part of the region (Figure 7(a)), the ISO activity is highly seasonal, when compared with WCA (Figure 7(b)). Both in the two subregions, the concavity of the curves changes around 120 and 320 days, but this change is sharper in ECA, when compared with WCA where the cumulative power increase almost uniformly. For both WCA and ECA, this percentage increases rapidly with time between 0 - 120 days and 320 - 365 days approximately. Moreover this value remains roughly constant between 120-320 days, corresponding to May-October season. Table 2 and Table 3 show a summary of the seasonality of the ISO. It is well seen that for WCA, about $60 \%$ (60.71\%, 57.92\%, 59.43\% for EOF1, EOF2 and EOF3, respectively) of the annual ISO activity occurs during November-April season, while in ECA this percentage reaches up to around 80\% (79.30\%, 78.02\%, 78.81\% for EOF1, EOF2 and EOF3, respectively).

It was proved by many previous studies that an important characteristic of the MJO (ISO) is its irregularity from year to another [7] [17] [39] [40]. One central question generally asked is how the ISO activity varies from year to year and how this interannual variability is linked with ENSO? Previous observation and modeling studies generally indicated that peak of MJO activity often precedes El Niño. Figure 8(a) \& Figure 8(b) shows the interannual variations in the ISO and ENSO signals. The two time series have been normalized for easy comparison. It can be seen from this figure that the ENSO experienced the highest fluctuations during the end of the years 1990's and the beginning of the years 2000's. For the two subregions, the evolution of ISO activity during 
WC A

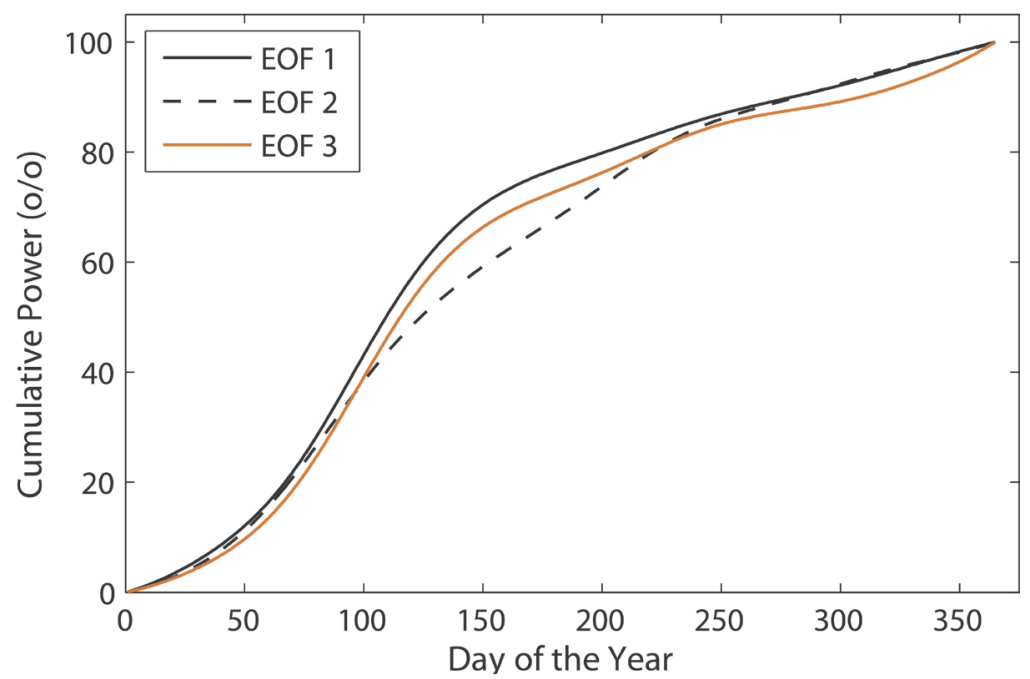

(a)

ECA

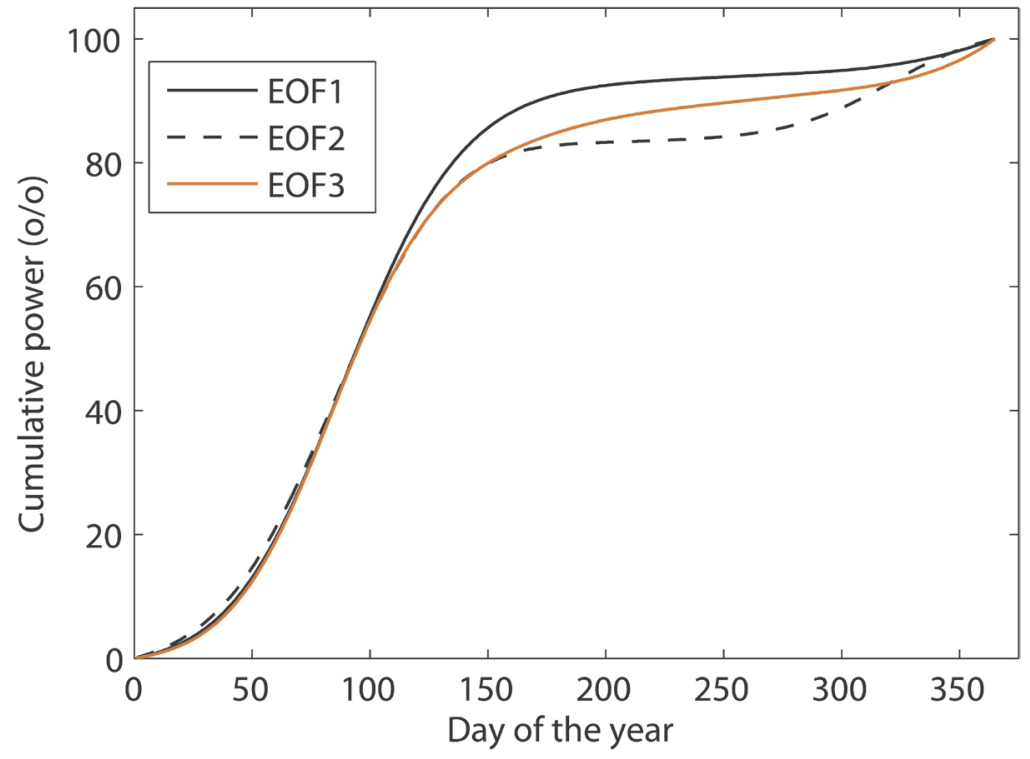

(b)

Figure 7. Cumulated percentage of mean ISO power for EOF1 (thin black), EOF2 (black dashed), and EOF3 (red), for WCA (a) and ECA (right).

Table 2. Distribution of the total annual ISO power in WCA, for October-April and May-September seasons.

\begin{tabular}{cccc}
\hline & EOF1 & EOF2 & EOF3 \\
October-April & $60.71 \%$ & $57.92 \%$ & $59.43 \%$ \\
May-September & $39.27 \%$ & $42.08 \%$ & $40.47 \%$ \\
\hline
\end{tabular}

Table 3. Same as Table 2, but for ECA.

\begin{tabular}{|c|c|c|c|}
\hline & EOF1 & EOF2 & EOF3 \\
\hline October-April & $79.30 \%$ & $78.02 \%$ & $78.81 \%$ \\
\hline May-September & $20.70 \%$ & $21.98 \%$ & $21.19 \%$ \\
\hline
\end{tabular}




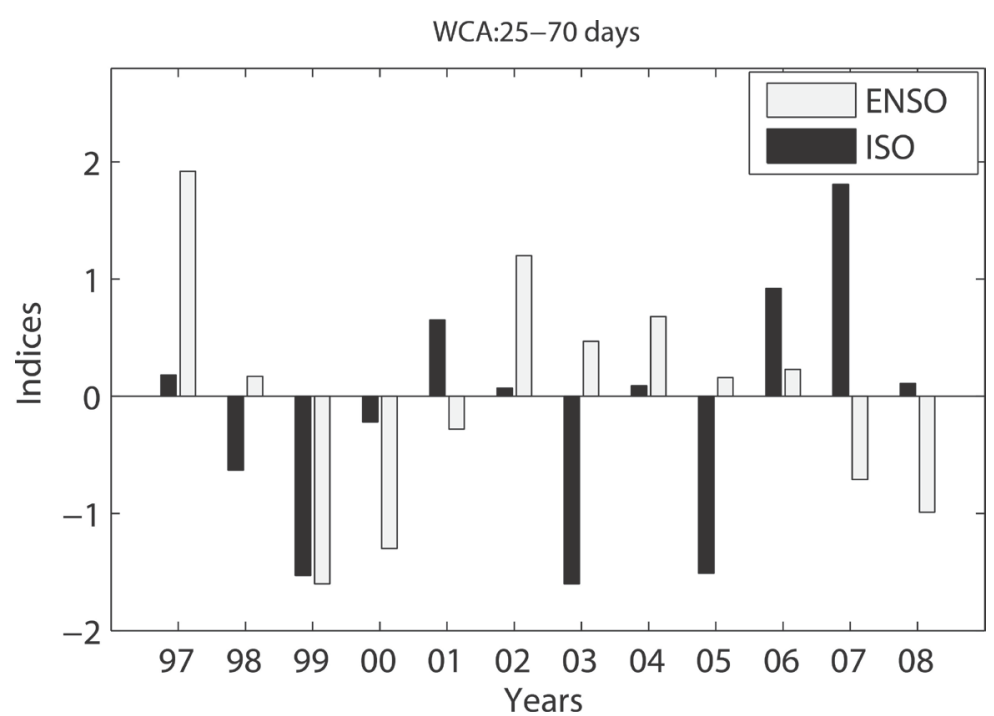

(a)

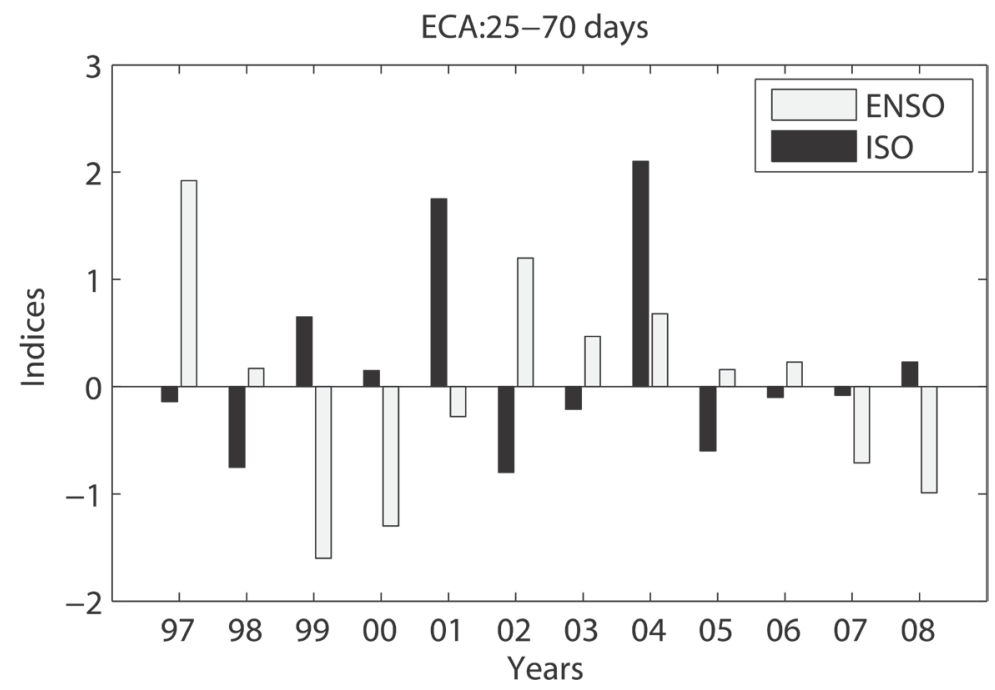

(b)

Figure 8. Interannual variations in the ENSO and ISO amplitude for the two subregions (WCA and ECA). The corresponding subregions are indicated on the top of each plot.

the end of the years 1990's and early 2000's are similar. The difference clearly appears toward the end of the study period. ECA is characterized by very low ISO activity during the years 2005-2008, while during the same period, the WCA experienced quite higher ISO activity in many years. The MJO and ENSO are dominant atmospheric and oceanic variability with different timescales, thus their relationship, is most likely nonlinear [41] [42]. However one should note that especially in ECA, the higher ISO activity often occur during cold or normal SST years, while the lower ISO amplitude are typically associated with warm SST years (Table 4).

\subsection{Relationship between WCA and ECA Modes}

It is well-known that the slow eastward propagation at an average speed of $5 \mathrm{~m} \cdot \mathrm{s}^{-1}$ is one of the most fundamental features that distinguishes the MJO from other phenomena in the tropical atmosphere, especially convectively coupled Kelvin waves, which propagate eastward at greater speeds of $15-17 \mathrm{~m} \cdot \mathrm{s}^{-1}$. This eastward propagation could potentially be the relationship between WCA and ECA modes of intraseasonal variability. In fact the correlation coefficients computed between the ISO indices of the same subregion end relatively high reaching up to 0.66 for PC1-PC3 (ECA) (Table 5). This suggests different mechanisms that induce rainfall variability at 
intraseasonal timescales in the two subregions. However the cross correlation between the indices of the different subregions are very low, except few of them, that reached up to 0.32 (Table 6), revealing once more that the eastward propagation could potentially be the relationship between WCA and ECA modes. Moreover in Figure 9 are displayed the lagged correlations between the WCA and ECA PC's time series. This figure clearly reveals that the observed PC's time series exhibit a characteristic lead/lag structure. The relatively high maximum positive correlation indicates that most of the WCA PC's leads ECA PC's time series with a time scale 8 - 12 days. This result suggests a zonal propagation of EOF modes found in the Section 3.2. Averaging filtered data between $15^{\circ} \mathrm{N}-15^{\circ} \mathrm{S}$, and plotting lagged correlation as a function of longitude, succinctly captures ISO propagation (Figure 10). Regression of the ISO indices [35] with filtered GPCP and $850 \mathrm{hPa}$ zonal wind is performed using the data over the central Africa $\left(15^{\circ} \mathrm{N}-15^{\circ} \mathrm{S} ; 0^{\circ} \mathrm{E}-50^{\circ} \mathrm{E}\right)$. The eastward propagation of the ISO is associated with low-level convergence. The $850 \mathrm{hPa}$ convergence anomalies lead the convection, showing enhanced easterlies (westerlies) ahead (behind) enhanced rainfall as the ISO propagates through the global tropics. The average duration of an intraseasonal event to move from $0^{\circ} \mathrm{E}$ to $50^{\circ} \mathrm{E}$ is about 10 days for a frequency around 40 days.

\section{Summary and Conclusions}

In this paper we have investigated the intraseasonal oscillations of rainfall over central Africa, using 1DD GPCP rainfall product, with an emphasis on the comparison between the western central Africa and the Eastern parts of the region. The classical spectral analysis showed the strong prominence of intraseasonal scale in central African climate, especially in ECA where the peak of the power spectrum is much sharp than WCA. On the other hand,

Table 4. Mean ISO and ENSO normalized indices for the two subregions, within the period 1997-2008.

\begin{tabular}{cccc}
\hline Year & ISO index WCA & ISO index ECA & ENSO index \\
\hline 1997 & 0.18 & -0.14 & 1.92 \\
1998 & -0.63 & -0.75 & 0.17 \\
1999 & -1.53 & 0.65 & -1.60 \\
2000 & -0.22 & 0.15 & -1.30 \\
2001 & 0.65 & 1.75 & -0.28 \\
2002 & 0.07 & -0.8 & 1.20 \\
2003 & -1.6 & -0.21 & 0.47 \\
2004 & 0.09 & 2.05 & 0.68 \\
2005 & -1.51 & -0.6 & 0.16 \\
2006 & 0.92 & -0.1 & 0.23 \\
2007 & 1.81 & -0.08 & -0.71 \\
2008 & 0.11 & 0.63 & -0.99 \\
\hline
\end{tabular}

Table 5. Correlation coefficients between WCA and ECA annual mean ISO power.

\begin{tabular}{lcc}
\hline & WCA & ECA \\
\hline PC1-PC2 & 0.58 & 0.47 \\
PC2-PC3 & 0.64 & 0.57 \\
PC1-PC3 & 0.49 & 0.66 \\
\hline
\end{tabular}

Table 6. Cross-correlation coefficients between WCA and ECA annual mean ISO power.

\begin{tabular}{|c|c|c|c|c|}
\hline & \multicolumn{4}{|c|}{ ECA } \\
\hline \multirow{4}{*}{ WCA } & & PC1 & PC2 & РC3 \\
\hline & PC1 & 0.13 & 0.32 & 0.14 \\
\hline & PC2 & -0.15 & 0.22 & 0.25 \\
\hline & PC3 & -0.04 & -0.37 & -0.05 \\
\hline
\end{tabular}



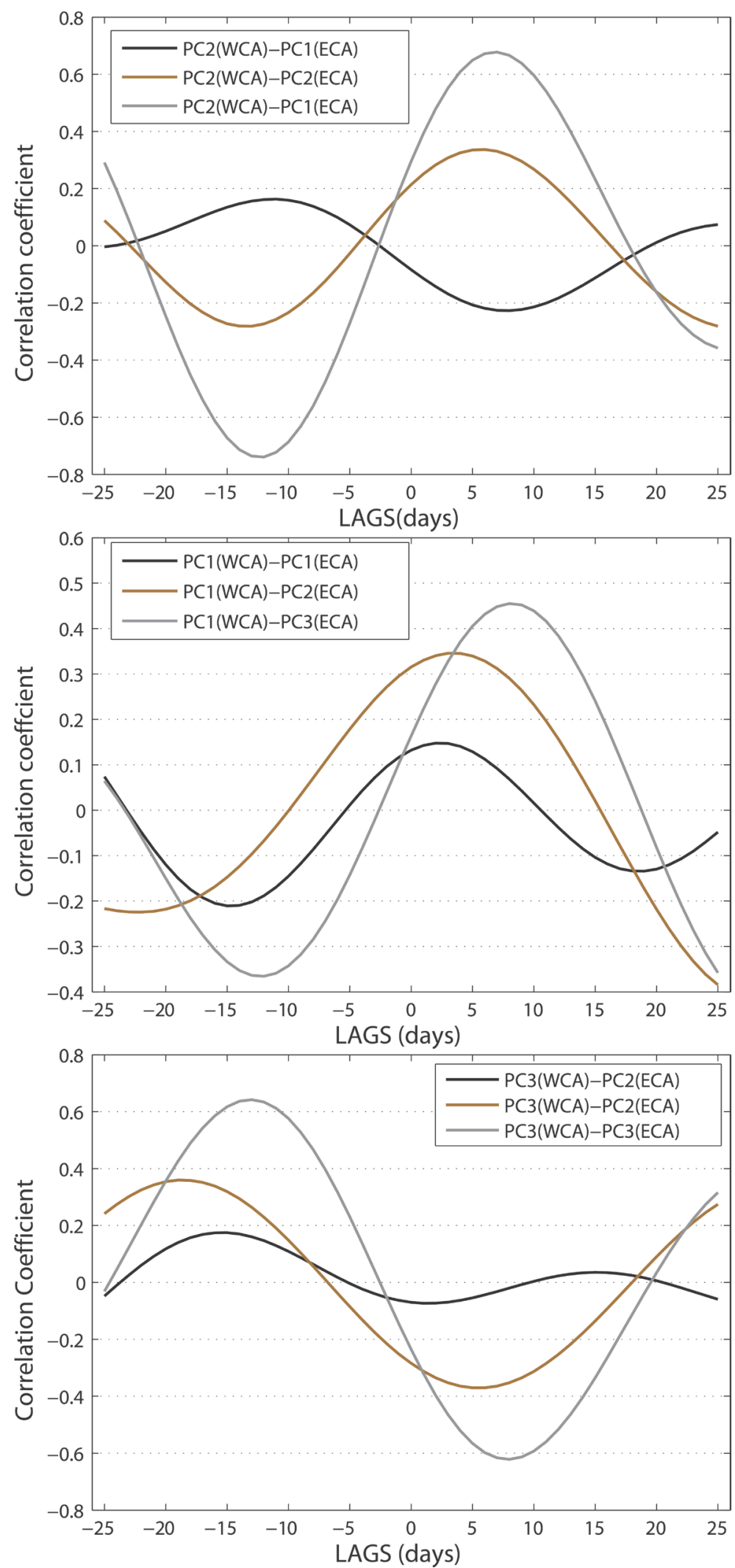

Figure 9. Lead-lag correlation between ECA and WCA 25 - 70-day PC's time series. Positive correlations at positive time lags indicate that convection over WCA leads that over the ECA. 


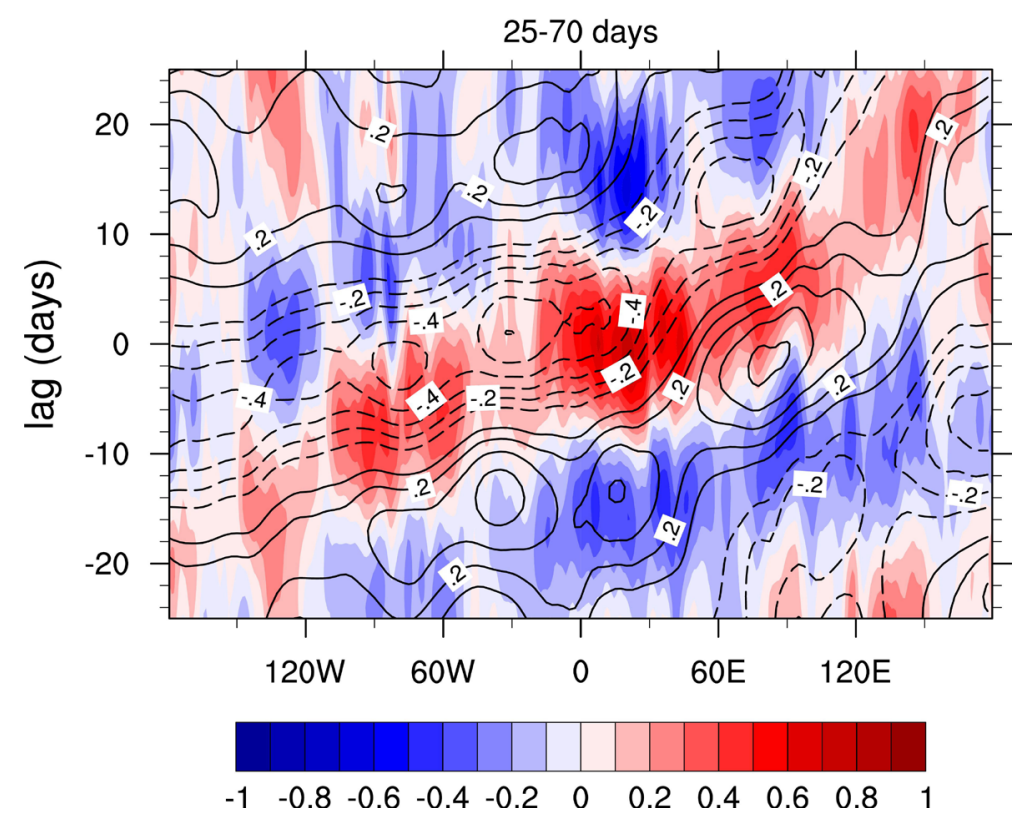

Figure 10. ISO composite based on the correlation between band-pass (25 - 70-day) filtered 850-hPa zonal wind (contours) and precipitation (colors) upon ISO index time series. The reference time series is the central Africa precipitation time series. The ISO index was computed using the average wavelet power.

a wavelet analysis revealed two dominant frequency bands in the intraseasonal rainfall variability in CA (10 - 25 days and 25 - 70 days), in accordance with the previous Fourier analysis. Moreover the seasonality of the ISO power is also revealed, because the maximum power is observed during the beginning and end of the year (October-April). But this seasonality is much highlighted in ECA, unlike WCA where the signal persists throughout the year.

The leading eigenvectors explain about $49.8 \%$ (that are 19.5\%, $15.7 \%$ and $14.6 \%$ for EOF1, EOF2 and EOF3, respectively) of total intraseasonal rainfall variability for WCA and $58.4 \%$ for ECA (that are $24.7 \%, 16.9 \%$ and $16.8 \%$ for EOF1, EOF2 and EOF3, respectively). The spatial loadings showed either positive or negative correlation coefficient between the PC's time series and 25 - 70-day filtered rainfall anomalies field. Both in ECA and WCA, the power spectra of the three leading EOFs peaked near 40 - 50 days, suggesting a MJO signal. As it could be expected from wavelet analysis above, the seasonality of the oscillations ISO is much clear in ECA, when compared with WCA. The lagged cross-correlations calculated between WCA and ECA PC's time series showed high maximum positive around 8 - 12 days, indicating that most of the WCA PC's time series leads ECA PC's time series with a time scale 8 - 12 days. This result confirmed that the relationship between WCA and ECA modes could be the eastward propagation of ISO signal through the global tropics.

To study much quantitatively the variations of ISO strength, an ISO index was built by averaging the daily wavelet power corresponding to each PC, to form a daily ISO index time series. The plot of ISO indices revealed that the ISO are highly seasonal, especially in ECA. In fact, almost $80 \%$ of the total yearly ISO power occurs during November-April season for ECA, against almost 60\% for WCA.

The plots of interannual variations of ISO and ENSO indices clearly show that the signal over ECA exhibits larger interannual variations than WCA. It has also been seen that ENSO and ISO fluctuated much during the end 1990's and beginning 2000's (1997-2008). Furthermore especially in ECA, the higher ISO amplitude generally corresponds to La Nina years (highly negative SST anomalies) or ENSO-neutral years, while the lower ISO amplitude generally corresponds El Nino years (highly positive SST anomalies).

The main conclusion that arises from these results is that the intraseasonal rainfall variability detected in 1DD GPCP rainfall reveals many different patterns in ECA and WCA. The major differences between WCA and ECA modes of variability are the annual and interannual variations in ISO strength. In fact the variations in WCA are weak, compared to ECA where the signal exhibits large annual and interannual variations. But the 1DD GPCP rainfall product is actually available over a short period (less than 20 years) and can't allow us to perform long-term analyses such as the interannual variations in the ISO activity and the relationships with low 
frequency phenomena such as ENSO.

\section{Acknowledgements}

Most of the scripts used in this study were produced from the NCL website http://www.ncl.ucar.edu. The GPCP data was obtained from the NOAA website, http://www.esrl.noaa.gov. All the administrator members of these websites are gratefully acknowledged for maintaining the updated data. We also thank the senior researchers of LEMAP and LISIE for helpful comments.

\section{Conflict of Interest}

The authors declare no conflict of interest.

\section{References}

[1] Thomas, M., John, C.H.C., Alexander, G. and Nicolas, J.C. (2009) Temporal Precipitation Variability versus Altitude on a Tropical High Mountain: Observations and Mesoscale Atmospheric Modeling. Quarterly Journal of the Royal Meteorological Society, 135, 1439-1455. http://dx.doi.org/10.1002/qj.461

[2] Vondou, D.A., Nzeukou, A., Lenouo, A. and Mkankam, K.F. (2010) Seasonal Variations in the Diurnal Patterns of Convection in Cameroon-Nigeria and Their Neighboring Areas. Atmospheric Science Letters, 11, 290-300. http://dx.doi.org/10.1002/asl.297

[3] Moore, A., Ioschnigg, J., Webster, P. and Leben, R. (2010) Coupled Ocean-Atmosphere Dynamics in the Indian Ocean during 1997-1998. Journal of Climate, 401, 356-360.

[4] Mutai, C., Hastenrath, S. and Polzin, D. (2007) Diagnosing the 2005 Drought in Equatorial East Africa. Journal of Climate, 20, 4628-4637. http://dx.doi.org/10.1175/JCLI4238.1

[5] Mitchell, T.P. and Wallace, J.M. (1992) The Annual Cycle in Equatorial Convection and Sea Surface Temperature. Journal of Climate, 5, 1140-1156. http://dx.doi.org/10.1175/1520-0442(1992)005<1140:TACIEC>2.0.CO;2

[6] Tsuneaki, S. (2011) Seasonal Variation of the ITCZ and Its Characteristics over Central Africa. Theoretical and Applied Climatology, 103, 39-60. http://dx.doi.org/10.1007/s00704-010-0276-9

[7] Madden, R.A. and Julian, P.R. (1994) Observations of the 40 - 50 Day Tropical Oscillation: A Review. Monthly Weather Review, 122, 814-837. http://dx.doi.org/10.1175/1520-0493(1994)122<0814:OOTDTO>2.0.CO;2

[8] Yamagata, T. and Hayachi, Y. (1984) A Simple Diagnostic Model for the 30 - 50 Days Oscillation in the Tropics. Journal of the Meteorological Society of Japan, 62, 709-717.

[9] Jury, M.R. and Mpeta, J. (2010) Intraseasonal Convective Structure and Evolution over Tropical East Africa. Climate Research, 17, 83-92.

[10] Jones, C., Higgins, R.W., Waliser, D.E., Schem, J.K.E. and Carvalho, L.M.V. (1999) Climatology of Tropical Intraseasonal Convective Anomalies 1979-2002. Journal of Climate, 17, 523-539. http://dx.doi.org/10.1175/1520-0442(2004)017<0523:COTICA >2.0.CO;2

[11] Harry, H.H. and Chindong, Z. (1996) Propagating and Standing Components of the Intraseasonal Oscillation in Tropical Convection. Journal of the Atmospheric Sciences, 54, 741-751.

[12] Camberlin, P. and Pohl, B. (2006) Influence of the Madden-Julian Oscillation on East African Rainfall. Part I: Intraseasonal Variability and Regional Dependency. International Journal of Climatology, 132, 2521-2539.

[13] Maloney, E.D. and Jeffrey, S. (2008) Intraseasonal Variability of the West African Monsoon and Atlantic ITCZ. Journal of Climate, 21, 2898-2918. http://dx.doi.org/10.1175/2007JCLI1999.1

[14] Slingo, J.M., Rowell, D.B., Sperber, K.R. and Nortley, F. (1999) On the Predictability of the Inner Annual Behavior of the Madden-Julian Oscillation and Its Relationship with El Niño. Quarterly Journal of the Royal Meteorological Society, 125, 583-609.

[15] Kessler, W. (1999) EOF Representations of the Madden-Julian Oscillation and Its Connection with ENSO. Journal of Climate, 14, 3055-3061. http://dx.doi.org/10.1175/1520-0442(2001)014<3055:EROTMJ >2.0.CO;2

[16] Hendon, H.H., Wheeler, M. and Zhang, C. (2007) Seasonal Dependence of the MJO-ENSO Relationship. Journal of Climate, 20, 531-543. http://dx.doi.org/10.1175/JCLI4003.1

[17] Tchakoutio, A.S., Nzeukou, A. and Tchawoua, C. (2012) Intraseasonal Atmospheric Variability and Its Interannual Modulation in Central Africa. Meteorology and Atmospheric Physics, 117, 167-179. http://dx.doi.org/10.1007/s00703-012-0196-6

[18] Haiyan, T. and Bin, W. (2003) Interannual Variations of the Boreal Summer Intraseasonal Oscillation in the Asian- 
Pacific Region. Journal of Climate, 16, 3572-3584.

http://dx.doi.org/10.1175/1520-0442(2003)016<3572:IVOTBS>2.0.CO;2

[19] Deng, L., Li, T., Liu, J., et al. (2016) Factors Controlling the Interannual Variations of MJO Intensity. Journal of Meteorological Research, 30, 328. http://dx.doi.org/10.1007/s13351-016-5113-3

[20] Gruber, A. and Krueger, A.F. (1984) The Status of the NOAA Outgoing Longwave Radiation Data Set. Bulletin of the American Meteorological Society, 65, 958-962. http://dx.doi.org/10.1175/1520-0477(1984)065<0958:TSOTNO >2.0.CO;2

[21] Hufman, G.J., Morrissey, M. and Bolvinetal, D. (2011) Global Precipitation at One Degree Daily Resolution from Multisatellite Observations. Journal of Hydrometeorology, 2, 36-50. http://dx.doi.org/10.1175/1525-7541(2001)002<0036:GPAODD>2.0.CO;2

[22] Adler, R.F. (2003) The Version-2 Global Precipitation Climatology Project (GPCP) Monthly Precipitation Analysis (1979-Present). Journal of Hydrometeorology, 4, 1147-1167. http://dx.doi.org/10.1175/1525-7541(2003)004<1147:TVGPCP>2.0.CO;2

[23] Arkin, P.A. and Meisner, B.N. (1987) The Relationship between Large Scale Convective Rainfall and Cold Cloud over the Western Hemisphere during1982-1984. Monthly Weather Review, 115, 51-74. http://dx.doi.org/10.1175/1520-0493(1987)115<0051:TRBLSC>2.0.CO;2

[24] McCollum, J., Nelkin, E. and Klotteretal, D. (20003) Validation of TRMM and Other Rainfall Estimates with a High-Density Gauge Dataset for West Africa, Part I: Validation of GPCC Rainfall Product and Pre-TRMM Satellite and Blended Products. Journal of Applied Meteorology, 42, 1337-1354.

[25] Dinku, T., Ceccato, P., Grover-Kopec, E., Lemma, M., Connor, S.J. and Ropelewski, C.F. (2007) Validation of Satellite Rainfall Products over East Africa’s Complex Topography. International Journal of Remote Sensing, 28, 15031526. http://dx.doi.org/10.1080/01431160600954688

[26] Ruiz, F., Dinku, T., Connor, S.J. and Ceccato, P. (2010) Validation and Intercomparison of Satellite Rainfall Estimates over Colombia. Journal of Applied Meteorology and Climatology, 49, 1004-1014. http://dx.doi.org/10.1175/2009JAMC2260.1

[27] Trenberth, K.E. (1997) The Definition of El Ninõ. Bulletin of the American Meteorological Society, 78, $2771-2777$. http://dx.doi.org/10.1175/1520-0477(1997)078<2771:TDOENO>2.0.CO;2

[28] Lanczos, C. (1956) Applied Analysis. Prentice-Hall, Upper Saddle River, 539 p.

[29] Duchon, C.E. (1979) Lanczos Filtering in One and Two Dimensions. Journal of Applied Meteorology, 18, $1016-1022$. http://dx.doi.org/10.1175/1520-0450(1979)018<1016:LFIOAT>2.0.CO;2

[30] Tchakoutio, A.S., Nzeukou, A., Tchawoua, C., Kamga, F.M. and Vondou, D. (2013) A Comparative Analysis of Intraseasonal Va-Riability in OLR and 1DD GPCP Data over Central Africa. Theoretical and Applied Climatology, 116, 37-49.

[31] Tchakoutio, A.S., Nzeukou, A., Tchawoua, C., Sonfack, B. and Siddi, T. (2013) Comparing the Patterns of 20-70 Days Intraseasonal Oscillations over Central Africa during the Last Three Decades. Theoretical and Applied Climatology, 118, 319-329.

[32] Torrence, C. and Compo, G.P. (1998) A Practical Guide to Wavelet Analysis. Bulletin of the American Meteorological Society, 79, 61-78. http://dx.doi.org/10.1175/1520-0477(1998)079<0061:APGTWA $>2.0 . C O ; 2$

[33] Cattell, R.B. (1996) The Scree Test for the Number of Factors. Multivariate Behavioral Research, 1, 245-276. http://dx.doi.org/10.1207/s15327906mbr0102_10

[34] North, G.R. Bell, T.L., Cahalanand, R.F. and Moeng, F.J. (1982) Sampling Errors in the Estimation of Empirical Orthogonal Functions. Monthly Weather Review, 110, 699-706. http://dx.doi.org/10.1175/1520-0493(1982)110<0699:SEITEO>2.0.CO;2

[35] Tchakoutio, A.S., Nzeukou, A., Tchawoua, C. and Siddi, T. (2014) On the Differences in the Intraseasonal Rainfall Variability between Western and Eastern Central Africa: Case of 10 - 25-Day Oscillations. Journal of Climatology, 2014, Article ID: 434960.

[36] Tazalika, L. and Jury, M.R. (2008) Intraseasonal Rainfall Oscillations over Central Africa: Space-Time Character and Evolution. Theoretical and Applied Climatology, 94, 67-80. http://dx.doi.org/10.1007/s00704-007-0349-6

[37] Rui, H. and Wang, B. (2010) Development Characteristics and Dynamic Structure of Tropical Intraseasonal Convection Anomalies. Journal of the Atmospheric Sciences, 47, 357-379. http://dx.doi.org/10.1175/1520-0469(1990)047<0357:DCADSO >2.0.CO;2

[38] Madden, R.A. and Julian, P.R. (1972) Description of Global-Scale Circulation Cells in the Tropics with a 40-50 Day Period. Journal of the Atmospheric Sciences, 29, 1109-1123.

http://dx.doi.org/10.1175/1520-0469(1972)029<1109:DOGSCC>2.0.CO;2 
[39] Huang, J. and Cho, H. (1998) Seasonal Modulated Intra-Seasonal Oscillations in a GCM simulation. International Journal of Climatology, 18, 1521-1532. http://dx.doi.org/10.1002/(SICI)1097-0088(19981130)18:14<1521::AID-JOC319>3.0.CO;2-1

[40] Hendon, H.H., Zhang, C. and Glick, J. (1999) Interannual Variation of the Madden Julian Oscillation during Austral Summer. Journal of Climate, 12, 2538-2550. http://dx.doi.org/10.1175/1520-0442(1999)012<2538:IVOTMJ>2.0.CO;2

[41] Hendon, H.H., Wheeler, M. and Zhang, C. (2007) Seasonal Dependence of the MJO-ENSO Relationship. Journal of Climate, 20, 531-543. http://dx.doi.org/10.1175/JCLI4003.1

[42] Tang, Y. and Yu, B. (2010) An Analysis of Nonlinear Relationship between the MJO and ENSO. Journal of Geophysical Research: Oceans, 86, 867-881.

\section{Submit or recommend next manuscript to SCIRP and we will provide best service for you:}

Accepting pre-submission inquiries through Email, Facebook, LinkedIn, Twitter, etc. A wide selection of journals (inclusive of 9 subjects, more than 200 journals)

Providing 24-hour high-quality service

User-friendly online submission system

Fair and swift peer-review system

Efficient typesetting and proofreading procedure

Display of the result of downloads and visits, as well as the number of cited articles

Maximum dissemination of your research work

Submit your manuscript at: http://papersubmission.scirp.org/ 